\title{
Pulmonary fibrosis following therapy with Melphalan for multiple myeloma
}

\author{
B. W. CODLING AND T. M. H. CHAKERA \\ From the Department of Pathology, the Medical School, Birmingham, and the Department of Radiology, \\ Queen Elizabeth Hospital, Birmingham
}

SYNOPSIS A patient suffering from multiple myeloma developed pulmonary fibrosis, of a type known to be associated wtih busulphan, whilst being treated with Melphalan.

The possible role of Melphalan as the causative agent is discussed. Reference is made to other possible aetiological agents and the reasons for their exclusion are discussed.

Following initial reports of diffuse interstitial fibrosis of the lung resulting from Busulphan therapy for myeloid leukaemia (Oliner, Schwartz, Rubio, and Damasheck, 1961; Leake, Smith, and Woodliff, 1963), the 'Busulphan lung syndrome' has become well recognized as a rare but important complication of treatment with Busulphan.

A case showing similar radiological and histological features arising for the first time following therapy with Melphalan for multiple myeloma is now reported.

\section{Case Report}

A male patient aged 62 had been treated for five months with methyldopa $250 \mathrm{mg}$ twice a day for hypertension. He was admitted on 18 September 1971 for investigation of a three-month history of backache associated with paraesthesiae of the legs.

A radiological survey of the skeleton showed multiple punched-out areas, especially in the skull and cervical spine, and collapse of the sixth thoracic vertebra.

The erythrocyte sedimentation rate (ESR) was $124 \mathrm{~mm}$ in one hr Westergren (normal 0-7 $\mathrm{mm}$ in one $\mathrm{hr}$ ). Serum electrophoresis showed a dense compact band between the $\beta$ and $\gamma$ globulin positions; hypercellular bone marrow aspirate containing large numbers of plasma cells $(56.25 \%)$ confirmed the diagnosis of multiple myeloma.

Initial treatment was with cyclophosphamide for one week (total dose $1.25 \mathrm{~g}$ ) plus radiotherapy to the mid-thoracic spine and sternum. This was followed by maintenance therapy of Melphalan $2 \mathrm{mg}$ twice a day and prednisone $10 \mathrm{mg}$ three times a day.

Received for publication 17 May 1972.
During his first admission to hospital he developed a chest infection with radiographic changes in both lower lobes. This resolved satisfactorily following treatment with ampicillin. At the time of discharge in November he was well and his chest radiograph was clear (Fig. 1).

On 19 December he was admitted as an emergency with a 10-day history of progressive dyspnoea following a 'chill'.

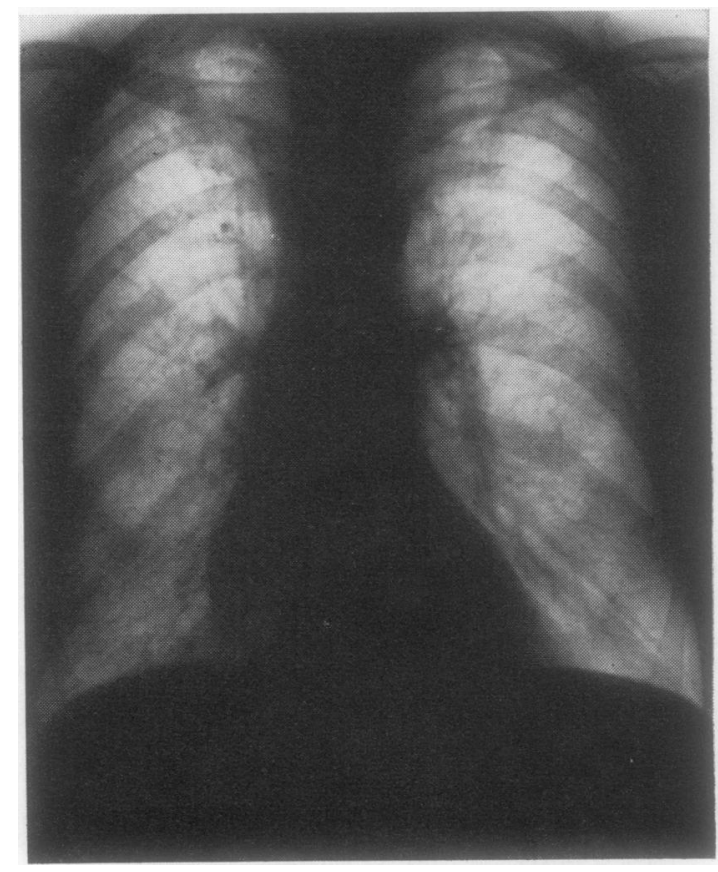

Fig. 1 Chest radiograph at the time of discharge in November 1971. 
Clinical examination revealed dyspnoea at rest and signs of widespread 'consolidation', maximal on the right. His blood pressure was $145 / 80 \mathrm{~mm} \mathrm{Hg}$, and there was no clinical evidence of congestive cardiac failure.

\section{INVESTIGATIONS}

\section{Blood count}

Haemoglobin $12.4 \mathrm{~g} / 100 \mathrm{ml}(100 \% 14.6 \mathrm{~g} / 100 \mathrm{ml})$. white blood cells $6000 / \mathrm{cmm}$ (normal $4000-11000 /$ $\mathrm{cmm}$ ), platelets $189000 / \mathrm{cmm}$ (normal $150 \quad 000-450$ $000 / \mathrm{cmm}$ ), ESR, $107 \mathrm{~mm}$ in one hr Westergren. Serum urea $69 \mathrm{mg} / 100 \mathrm{ml}$ (normal $10-45 \mathrm{mg} / 100 \mathrm{ml}$ ).

\section{Blood gases}

$\mathrm{PCO}_{2} 46 \mathrm{~mm} \mathrm{Hg}$ (normal $35-45 \mathrm{~mm} \mathrm{Hg}$ ), $\mathrm{PO}_{2} 54 \mathrm{~mm}$ $\mathrm{Hg}$ (normal $80-100 \mathrm{~mm} \mathrm{Hg}$ ), $p \mathrm{H} 7.48$ (normal 7.38-7.44), and standard bicarbonate $32.5 \mathrm{~m}$ equiv/l (normal 22-26 m equiv/l).

\section{Bacteriology}

Sputum yielded a moderate growth of normal commensals sensitive to the antibiotic therapy being given (ampicillin).

Treatment with Melphalan was stopped and prednisolone substituted for the prednisone, initially

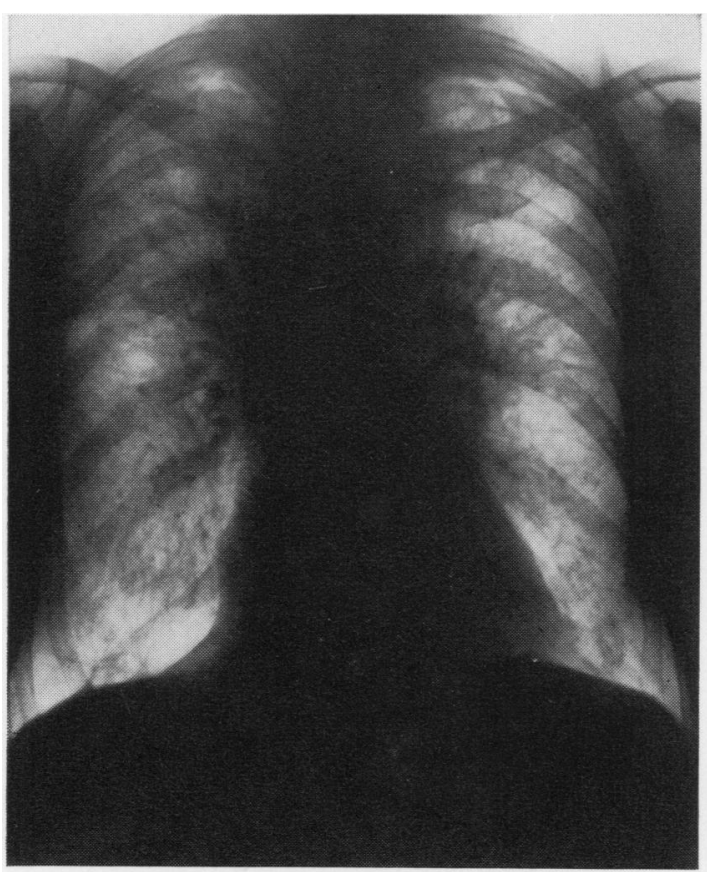

Fig. 2 Chest radiograph at the time of final admission in December 1971.
$30 \mathrm{mg}$ twice daily decreasing to $20 \mathrm{mg}$ twice a day over a period of five days.

A chest radiograph now showed widespread fine nodular $(0.5-1.00 \mathrm{~mm})$ and linear opacities involving both lungs diffusely but most striking in the upper zones and perihilar regions. In addition there was elevation of the lesser fissure suggesting loss of volume of the right upper lobe.

The heart was not enlarged (transverse diameter $14.0 \mathrm{~cm}$, normal up to $15.5 \mathrm{~cm}$ ), the same size as on the first admission, and there were no septal lines to suggest congestive cardiac failure (Fig. 2).

Multiple rib fractures were also noted on the radiograph.

Despite treatment with steroids and antibiotics his condition progressively deteriorated. The dyspnoea increased and there was marked arterial oxygen desaturation with hypercapnia and terminal rise in blood urea (highest value recorded $151 \mathrm{mg} / 100 \mathrm{ml}$ ) before he died on 2 January 1972.

\section{Postmortem Findings}

The major findings at necropsy were confined to the respiratory system and skeleton, which showed widespread involvement with multiple myeloma. Changes in the cardiovascular system consistent with moderate systemic hypertension were present (heart weight $410 \mathrm{~g}$, normal up to $340 \mathrm{~g}$ ), left ventricle $1.6 \mathrm{~cm}$ thick (normal up to $1.4 \mathrm{~cm}$ )). The right ventricle showed no evidence of hypertrophy.

The pleurae were normal. Small, clear, bilateral effusions were present. Both lungs retained their shape on removal from the chest and were firmer than normal. The right lung on section showed a variegated grey and yellowish appearance, with areas of haemorrhage. The left lung was fixed inflated by infusion of formol saline into the bronchial tree. When fixed the lung was cut into $1 \mathrm{~cm}$ thick serial slices. The cut surface showed a solid appearance with obliteration of many alveoli by fibrous tissue and with dilatation of alveoli and alveolar ducts. Progression to an early honeycomb pattern in some areas (Fig. 3) was seen with abnormal air spaces measuring up to $2 \mathrm{~mm}$ in diameter (normal alveoli 250-350 $\mu$ diameter and alveolar ducts up to $470 \mu$ in diameter).

\section{Histology}

There was extensive involvement of bone marrow by deposits of myeloma.

The lungs showed proliferation of alveolar lining cells. These appeared as large eosinophilic cells with abundant granular cytoplasm, large vesicular 


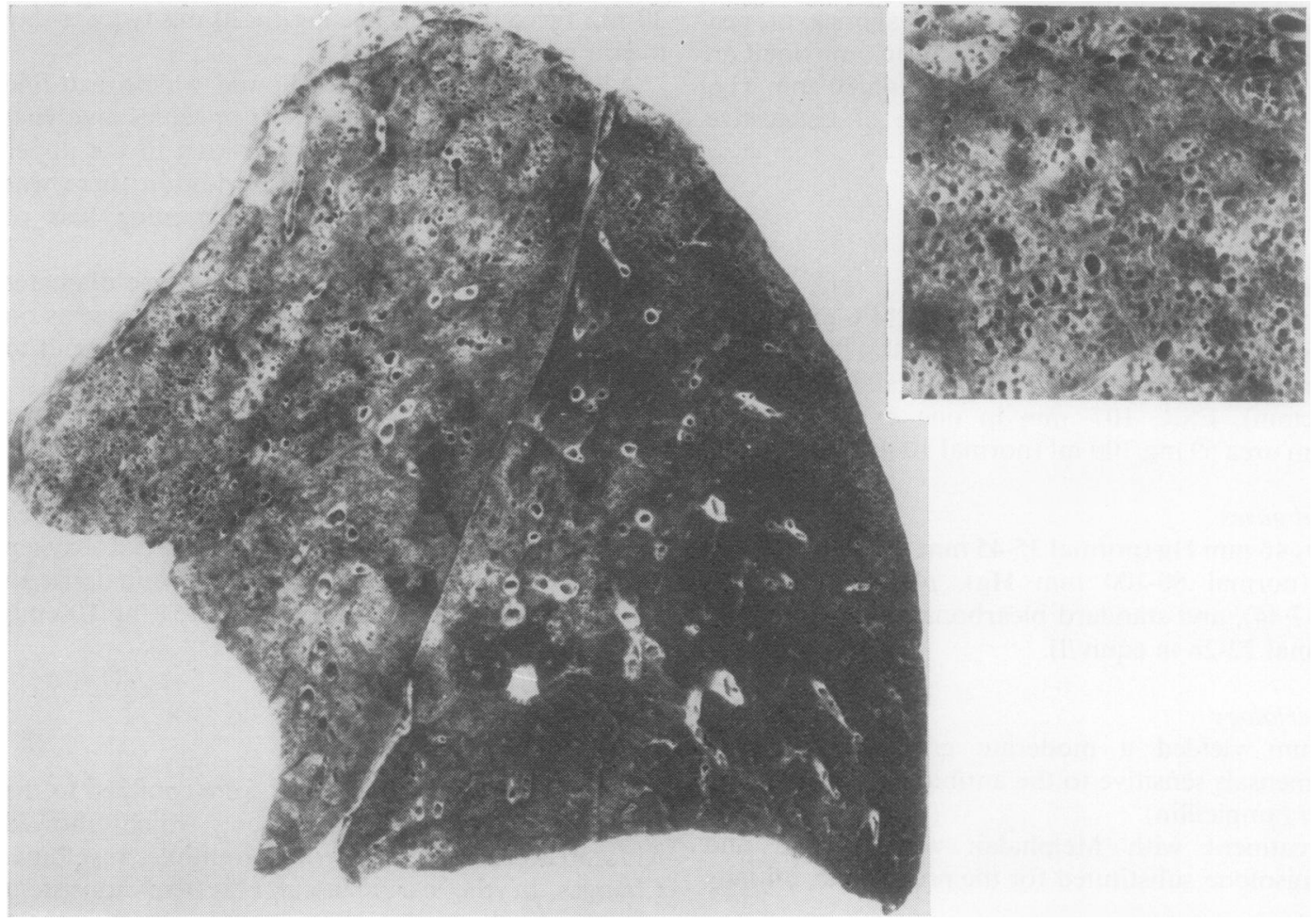

Fig. 3

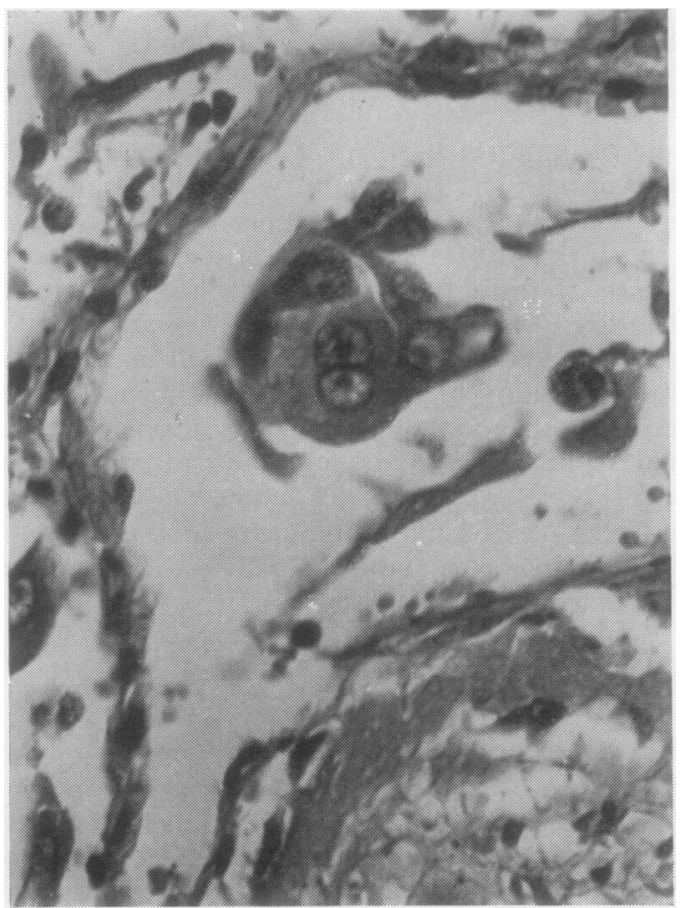

Fig. $31 \mathrm{~cm}$ slice from the mid portion of left lung. Inset, a close up of the anterior part of the upper lobe.

Fig. 4 Alveolus containing hyperplastic alveolar lining cells with giant cells. The alveolus also contain fibrinous exudate. H. \& E. $\times 520$.

Fig. 4 


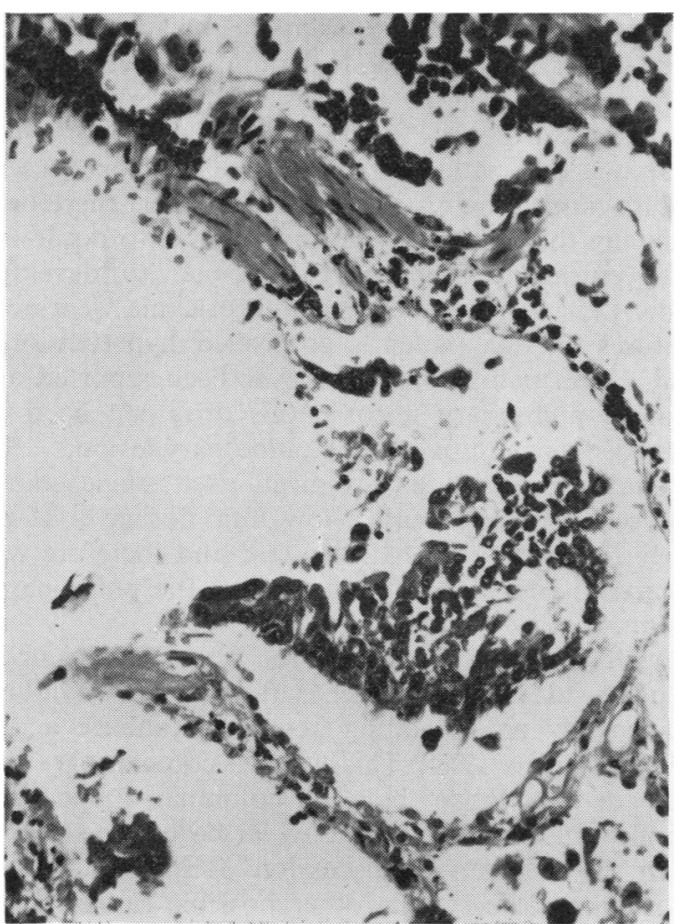

Fig. 5



Fig. 7

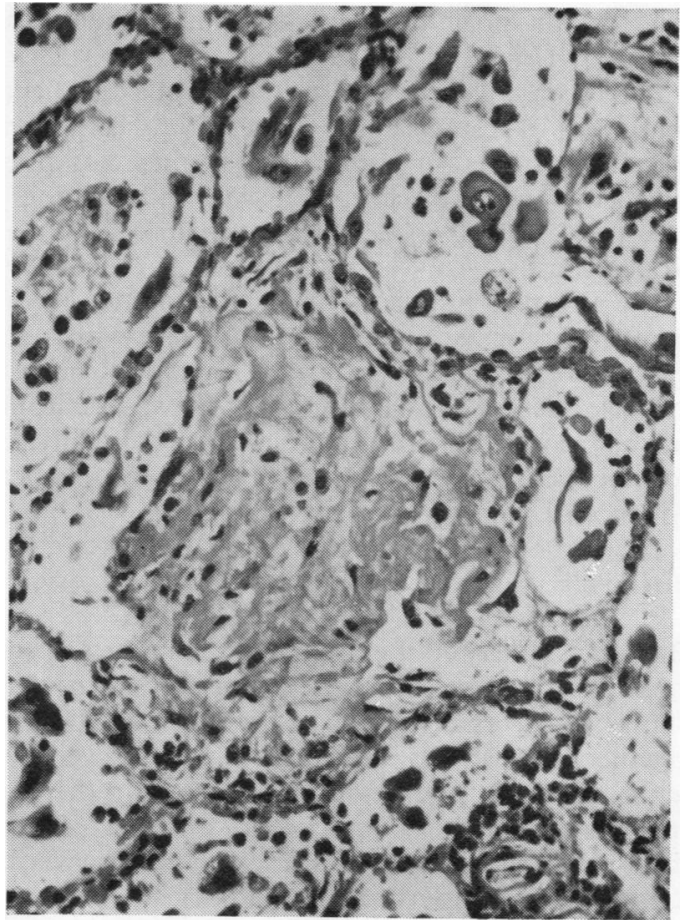

Fig. 6

Fig. 5 Terminal bronchiole showing hyperplastic epithelium. H. \& E. × 195.

Fig. 6 Alveoli containing fibrinous exudate with hyperplastic lining cells also. H.\& E. $\times 195$.

Fig. 7 Obliteration of alveoli by fibrous tissue. $H . \& E$. $\times 195$. 
nuclei with prominent nucleoli, and giant cell formation (Fig. 4).

There was also proliferation of the epithelial lining cells of terminal bronchioles (Fig. 5). In some areas this proliferating epithelium formed clumps of cells surrounded by fibrous tissue and bearing a superficial resemblance to the 'tumourlets' seen in bronchiectasis.

The alveoli contained a fibrinous exudate (Fig. 6) showing organization by fibrous tissue with obliteration of air spaces (Fig. 7). Interstitial fibrosis was also present and in addition there was a chronic inflammatory cell infiltrate consisting mainly of normal plasma cells. There was no histological evidence of pulmonary hypertension.

\section{Discussion}

The lung changes in the present case are the same as those described as complicating busulphan therapy. The changes associated with busulphan therapy, together with similar reactions following severe left ventricular failure, uraemia, nitrofurantoin therapy, and therapy with hexamethonium and related ganglion-blocking agents, have been reviewed by Kirschner and Esterly (1971). Other factors associated with similar pulmonary changes include irradiation (Smith, 1963), intermittent positive pressure ventilation (Hall and Margolin, 1972), and bleomycin therapy (Fleischman, Baker, Thompson, Schaeppi, Illievski, Cooney, and Davis, 1971). The features of this patient's illness which had to be considered as possible causes of the pulmonary disorder were irradiation, myeloma infiltration, uraemia, methyldopa, cyclophosphamide, and Melphalan.

It is difficult to assess accurately the effects of irradiation in this case. The patient received a total of 3000 rads (skin dose) in 10 fractions over 14 days from a $230 \mathrm{KV}$ unit.

The fields irradiated were $10 \times 12 \mathrm{~cm}$ posteriorly to the mid thoracic vertebrae and $12 \times 15 \mathrm{~cm}$ anteriorly to the sternum. The calculated total central mediastinal dose (antero-posterior diameter $24 \mathrm{~cm}$ ) was 1320 rads. This dose is below that generally recognized as causing radiation fibrosis (Jennings and Arden, 1962). Moreover the radiological and histological changes described were not, in this case, confined to the narrow, central irradiated area.

Myeloma infiltration of the lung is well documented (Gabriel, 1965). The present case showed no evidence of pulmonary involvement and plasma cells in the inflammatory infiltrate were present in similar numbers to those noted in a case of busulphan lung (Rushton, 1972).

Doubt has been cast on the role of hexamethon- ium and related blocking agents as prime causative agents in the development of pulmonary lesions in hypertensive patients. Park and Cockersole (1956) regard the role of the drug therapy as one of enabling the patient with severe left ventricular failure and uraemia to survive longer therefore allowing the pulmonary lesions, known to occur in left ventricular failure and uraemia, to develop fully. Left ventricular failure and uraemia were not features of this patient's controlled hypertension, and, since methyldopa has never been reported as causing pulmonary fibrosis, this drug can be disregarded as causative of the pulmonary lesion.

Cyclophosphamide was given as a single short course (one week) with a low total dosage $(1.25 \mathrm{~g})$ early in the course of the disease and therefore we regard this as an unlikely cause of the pulmonary lesion.

Melphalan is a phenylalanine nitrogen mustard, a powerful cytotoxic agent affecting the dividing nucleus by an alkylating action on nucleic acids (Waldenstrom, 1964). This action is comparable with o that of busulphan but no pulmonary reactions implicating Melphalan have so far been recorded.

In the case under discussion Melphalan is the most likely cause since other possible causes have been excluded on clinico-pathological grounds.

Littler, Kay, Hasleton, and Heath (1969) consider that the changes in busulphan lung result from a direct toxic effect of the drug on type II (granular) pneumocytes resulting in their proliferation and subsequent disintegration to produce intraalveolar debris associated with fibrinous oedema. This then becomes organized by fibrous tissue with fibrosis of alveolar septae also. This mechanism of development was regarded as a non-specific reaction which could develop in response to a wide variety of noxious agents. In the particular case this is rather curious, since the stimulus is a drug known to have an alkylating action on the nucleic acids of the dividing nucleus.

Why the intraalveolar exudate is organized by $\frac{D}{O}$ fibrous tissue rather than removed by the processes of fibrinolysis and phagocytosis is not understood. $N$ Various explanations have been postulated, including $N$ defective fibrinolysis preventing dissolution of the $N$ fibrin component of the exudate (Park and Cocker- $\omega$ sole, 1956) and deficiency of leucocytes and macrophages resulting in the failure of the removal of debris.

Defective fibrinolysis may be due either to stabilization of the fibrin rendering it resistant to fibrinolysis, deficient production of fibrinolysins, or $\frac{\overrightarrow{\mathbb{P}}}{\mathrm{D}}$ inhibition of fibrinolysins. These effects may possibly $\frac{\rho}{\mathbb{D}}$ be caused either as a direct effect of the causative $\varrho$ agent, Melphalan in the present case, or possibly due 
to a product of the disintegrating type II pneumocyte.

In the present situation Melphalan may be important in inhibiting the removal of intraalveolar debris by its toxic effect on phagocytes.

We thank Dr G. E. Owen Williams for permission to publish the clinical details of this case, Dr G. A. Newsholme and Professor D. B. Brewer for their help in the preparation of the manuscript, and Miss G. L. Parkinson for typing the manuscript.

Requests for reprints should be addressed to B. W. Codling, Department of Pathology, Medical School, University of Birmingham, P. O. Box 363, Edgbaston, Birmingham B15 2TJ, England.

\section{References}

Fleischman, R. W., Baker, J. R., Thompson, G. R., Schaeppi, U. R., Illievski, V. R., Cooney, D. A., and Davis, R. D. (1971).
Bleomycin-induced interstitial pneumonia in dogs. Thorax, 26, 675-682.

Gabriel, S. (1965). Multiple myeloma presenting as p:lmonary infiltration. Dis. Chest, 47, 123-126.

Hall, R. M., and Margolin, F. R. (1972). Oxygen alveolapathy in adults. Clin. Radiol., 23, 11-17.

Jennings, F. L., and Arden, A. (1962). Development of radiation pneumonitis. Arch. Path., 74, 351-360.

Kirschner, R. H., and Esterly, J. R. (1971). Pulmonary lesions associated with busulfan therapy of chronic myelogenous leukaemia. Cancer (Philad.), 27, 1074-1080.

Leake, E., Smith, W. G., and Woodliff, H. J. (1963). Diffuse interstitial pulmonary fibrosis after busulphan therapy. Lancet, 2 , 432-434.

Littler, W. A., Kay, J. M., Hasleton, P. S., and Heath, D. (1969). Busulphan lung. Thorax, 24, 639-655.

Oliner, H., Schwartz, R., Rubio, F., Jr., and Damashek, W. (1961). Interstitial pulmonary fibrosis following busulfan therapy. Amer. J. Med., 31, 134-139.

Park, W. W., and Cockersole, F. J. (1956). Hexamethonium lung. J. Obstet. Gynaec. Brit. Emp., 63, 728-734.

Rushton, D. I. (1972). Personal communication.

Smith, J. C. (1963). Radiation pneumonitis. Amer. Rev. resp. Dis., 87, 647-655.

Waldenström, J. (1964). Melphalan therapy in myelomatosis. Brit. med. J., 1, 859-865. 